\title{
HISTORY AND MYSTICISM IN ROY FISHER'S A FURANCE
}

\author{
Assistant Professor Nadia Ali Ismael (PhD) \\ University of Baghdad/College of Languages/Department of English
}

DOI: $10.37648 / \mathrm{ijrssh} . v 10 \mathrm{i01.041}$

Received: $17^{\text {th }}$ November 2019; Accepted: $17^{\text {th }}$ December, 2019; Published:11 $1^{\text {th }}$ January, 2020

\begin{abstract}
A Furnace was Roy Fisher's second-biggest masterpiece following the publication of City. However, different from his other works, A Furnace offers its reader a genius perspective on how to write about place and time. The poem provides a mystical way through which events happening at a given place are phenomenologically recorded. The poem talks about the structure and design of the path into and out of life, opening the doorway to a realm of mysticism. Together with the use of history, Fisher sets out to address his main agenda of the poem which is to explain the path from birth to death. He makes it possible to understand the happenings of events at any given place or time through the use of these two concepts. As from the results, it is apparent that mysticism and history serve great importance to Fisher's poem as they allow him to express his rather sophisticated perspectives in a reader-friendly manner.In this essay, the main aim will be to examine Fisher's poetry, to determine the importance of the use of history as well as mysticism in the poem. The study is conducted through an in-depth analysis of the poem as well as relevant scholarly sources that are related to the poem. The analysis of mysticism and history is carried out in two different sections, and an effectiveness section accompanies each of them.
\end{abstract}

Key words: Fisher, history, mysticism, poem, Furance.

\section{THE IMPORTANCE OF HISTORY AND MYSTICISM IN ROY FISHER'S A FURNACE}

\subsection{Mysticism}

Roy Fisher's,AFurnace, is riddled with many instances of mysticism that have massive contributions to the development of the structure and design of the poem. By definition, mysticism refers to ideologies or beliefs that are not in line with the doctrines of the church. These are concepts which are otherwise considered taboo to be discussed in holy discussions, Fisher's poem is riddled with the use of mysticism straight from the beginning. For example, Fisher suggests that the world has evolved far beyond the designs of the designer, and whatever the intentions of the designer, the world has eventually come to absorb them and move on with life. Such claims refute the existence of a reigning supernatural being, which is contradictory to most religious views.

However, in his poem, A Furnace, Fisher uses most of the mysticism to develop his main narrative, which explains the structure of the path in and out of life.The structure and design of A Furnace present readers with ambiguous manners through which time can be understood and perceived. By nature, the poem takes the structure of a double spiral originating from a central 
core. “...the seven movements [of A Furnace] proceed as if by a section taken through the coreof such a spiral, with the odd-numbered ones thematically touched by one direction of thespiral's progress, and the evennumbered so touched by its other, returning, progress" (Pople 85).

Fisher describes the double spiral,

We're carving the double spiral

into this stone; don't

complicate or deflect us.

We know what we're at.

We're letting the sun perceive

we've got the hang of it.

Write sky-laws into the rocks;draw

the laws of light into it and through it.

(Fisher71)

Fisher's poem is clear about the dimensionality of time, which is a concept that may not be entirely welcome especially among religious audiences.

In his preface, Fisher also acknowledges the design of time to be a double spiral. "The sequence of is movements is based on a form which enacts, for me, the equivocal nature of the ways in which time can be thought about.This is the ancient figure of the double spiral; whose line turns back on itself at the center and leads out against its own incoming curve."(v11-v111)In order to illustrate the dimensionality of time in the poem, Fisher uses the musical term, 'movement' in his description of sections within the poem, and the word 'proceed' for reinforcement purposes.

As apparent from A Furnace, the proceeding of movement is in time and through time, as well as the movement in and out of life (Pople 86).The use of a double spiral to represent the nature of time is even apparent from the poem's use of a double spiral design on the cover of the first Oxford Edition of the poem. From the cover, Roy Fisher also indicates that the movement through time on its own is porous in nature.
In the cover, the spiral line is not solid and appears like a child's drawing, and this serves as an indication that movement in time is not steady, but somewhat porous. The importance of employing mysticism through the use of the double spiral design is that it aids the author in passing his main points in the poem, which is the emphasis on the nature of time.

In A Furnace, part of Fisher's main agendas is to generate an intellectual reach towards the comprehension of the relationship that exists between time and movement (Pople 85). Intellectual reach or noetic reach in poetry simply refers to the ability of a poem to get people interested in topics that would generally be perceived as intellectual. For example, a poem may discuss topics that are not realities, but making the readers engage with those realities through their imagination would be a key goal for the author, thus calling for noetic reach. In the poem, $A$ Furnace,Fisher engages the reader in an intellectual imagination through his notions of the cosmology.

However, his version of the cosmology is not in line with the radical noesis of the nature of the cosmos. Fisher's A Furnace presents a movement and progression through the double spiral of time that can be mapped into a labyrinth. What this means is that it presents a lot of mental challenges to progress through the labyrinth, which makes the possibility of making an exit uncertain. As a result, this would seem to imply that death may not be definite in Fisher's double spiral pattern. Therefore, a theme of timeless identities entering nature becomes developed at this juncture, as the movement is from outside time into time (Pople 86).

Fisher's use of mysticism in the poem has paved the way for intellectual debate concerning his intended meanings as the mysticism is responsible for abstracting his intentions. As a result, different interpretations of his design and structure of time have been developed. Crozier is one of the scholars that describe the pattern of A Furnace as a labyrinth enclosure. However, Crozier heavily shuns the notion that such a model is mystical in nature (Pople 86). He denies the poem's mysticism because of the fact that it does not arrive at a heterodox mysticism, and as a result, it annuls the fact that death is existent in the world. 
Of course, the mental challenge that was presented by Fisher's use of mysticism has not deterred other brilliant minds from expressing views that differ from that of Crozier. For example, Brown contests this position through presenting the argument that a labyrinth differs from a maze in nature. Ideally, labyrinths marked the floors of cathedrals, Chartres, and Auxerre, and they were symbols of pilgrimage (McAuliffe et al.). The journeys made by pilgrims were often as a result of circumstances, but the pilgrims would almost be certain of reaching their end destination provided they remained focused on their paths.

Therefore, what this means is that if Crozier considers Fisher's design and pattern to be a labyrinth, then it would mean that death has not been taken out of the picture. As a result, the mysticism remains in the poem as it does not propose a theory that is completely irrefutable (Crook 424). Later on, in the poem, Fisher returns to the description of the path, hence finally refuting Crozier's claim that the path might as well be a labyrinth.

"But still through that place to enter Nature; it was possible, it was imperative. Something always coming out, back against the flow, against the drive to be in, close to the radio, the school, the government's wars; the sunlight, old and still, heavy on dry garden soil, and nameless mouths, events without histories, voices, animist, polytheist, metaphoric, coming through; the sense of another world not past, but primordial, everything in it simultaneous, and moving every way but forward" (Fisher 2). From lines such as "something always comes out" allude to the fact that there must always be an entry from the path of life. Therefore, this clearly shows that Crozier's assumption that there could be a path into life that would not have an exit, hence denying the surety of death, unacceptable.

So, what is the nature of the movement within the double spiral labyrinth of time? In order to fully answer this question, it is essential to reflect on the nature of the movement within the perceived mysticism (McAuliffe et al.). As apparent from Crozier and Brown, in recent years, writers have often shunned an experiential model of mysticism, in favor of a teleological theology. A teleological theology refers to writings that have an intellectual and epistemological reach through experiences that are explained following an apophasis (Pople 87). As a result, this means that mysticism in the medieval age was a product of the experience of the writing.

The argument is identical to one presented by McGinn, in which he proposes mysticism to be as a product of Romanticism (Ingne 53). In Roy Fisher's Furnace, romanticism is evident as he clearly embraces English Romanticism. The ideas and concepts that Fisher presents in his poem heavily borrow from John Cowper Powy's work, Atlantis (Ingne 53). In Cowper's romance story, 'Atlantis,' a ruler of a sunken city is featured as an author of a long poem that describes the beginning to the end of the world. In the narrative of the beginning to the end of time, the author employs the use of landscape superimposed against landscape, instead of rhythm upon rhythm to pass the central message of the poem. Similar to Atlantis, A Furnace superimposes different landscapes against each other in order to explore the various possible beginnings and endings in order to generate transparency in time.This perception is detailed in the poem:

\author{
The method \\ of the message lost/in the poetry of Atlantis \\ at its subsiding to where all \\ landscapes must needs be \\ superimpositions on it.All landscapes \\ solid,and having transparency \\ in time, in state.
}

(Fisher 41)

Romanticism is also evident in Roy Fisher's use of Powy's metaphysics and mysticism. As Fisher borrows from Powy's Romanticism, his use of landscapes also serves a significant boost in his poem. Fisher employs a genius method to give narratives about different locations based on a unique point of view that he uses to look at the places. For Fisher, the places and events taking place are interconnected to other events taking place at different locations and at different times. 
Therefore, through the Romanticism borrowed from Powy's Fisher is able to elaborate better his ideas on the nature of the path into and out of life (Bracey and Payne 49).

Straight from the beginning of the poem, mysticism is apparent. Different from most literal works that begin with a preface section, the preface to Fisher's poem is written as an 'Introit' which offers the opening scene to the poem. In the beginning, the date is set as $12^{\text {th }}$ November 1958 , and the aura that is set is akin to a secular afflatus. The narrator is situated on the top of a bus and is observing the town of Birmingham. At this stage of the poem, the narrator establishes himself as the 'light divider' during the late autumn shine (Ingne 53).

"Whatever approaches my passive taking-in, then surrounds me and goes by will have itself understood only phase upon phase by separate involuntary strokes of my mind, dark swings of a fanblade that keeps a time of its own, made up from the long discrete moments of the stages of the street, each bred off the last as if by causality" (Fisher 2-3). Through the manner that Fisher describes the narrator in his introit, the readers are set to expect a secular mood in which they are set to prepare themselves for a cosmology filled with whatever it besets upon them (Mirabai)

As apparent with the poem AFurnace, Fisher associates the use of mysticism with the reception of light (Ingne 53). Fisher embodies light in his poetry to move with agency and intention, hence helping him in the creation of a concept that is contrary to traditional belief. At the introit, when Fisher refers to the narrator as the 'light divider,' he is also reckoned as the 'knifeblade.' As Fisher positions the metaphor of light with the metaphor of knifeblade, he opens up a gateway towards a metaphysical realm (Crook 420).He says:

and as if I was made

to be theknifeblade, the light-divider,

perpetusally

to my right the brilliance strikes out into the brick house-fields towards Wolverhamton, their calculable distances

shallow with detail

(Fisher 2).

The knife blade mentioned in the metaphor incises the world at the point where Fisher is and opens up a gateway towards the second metaphor. As the knife divides the light, the light emerges to provide warmth and sight. Light, as portrayed by the author, does not only offer these advantages, but it also appears to have specificcharacteristics. The characteristics include caprice, intention, and agency. The purposes of the light are aimed at ensuring that it possesses noetic illumination properties, which the speaker cannot perceive to be unaided by prominent forces (Spence 70). As the poem implies such, it ventures dipper into the mystical realm.

"This light is without rarity, it is an oil, amber and clear that binds in this alone and suggests no other. It is a steady medium, agent to a purpose" (Fisher 2). A lot of mysticism lies underneath these quotes from Fisher's Furnace. In the real world, light does not operate out of agency, and neither does it seek to accomplish any meaningful purpose. However, Fisher portrays light as a manifestation capable of achievements, and that can improve the position of whomever it shines within, depending on the purpose. Of course, through the light metaphor, Fisher is referring to the noetic reach within his poem. As earlier stated, the poem is meant to act like the light-bringer. The primary purpose of the poem is to provide illumination with regards to life and mortality matters, which are subjects that lack extensive knowledge as per religious knowledge. However, since such topics are rarely discussed publicly for the nature of their depth, Fisher attempts to give his readers insight into the matter through the poem which is the knowledge bringer. Through this perspective, the effectiveness of Fisher's use of mysticism and metaphysics becomes apparent.

Once the light or the illumination has been taken in, it holds on to itself as well as the person in which it resides. In this way, the light remains always to be exclusive, yet unique. In the poem, the light enables the narrator to feel for a cosmology. In literal terms, such 
metaphors used by Roy Fisher would represent the illuminated nature that one gets to attain once the light has got to reside within them. However, as Fisher places it, the light is supposed to enable the beholder to feel for more cosmology, and this bears a mystical innuendo. Since such actions are physically impossible, it appears as though one is compelled to step into the metaphysical realm for Roy Fisher's words to become a reality.

There may also be another reason as to why Fisher saw it fit to employ the use of mysticism in his work. Up to now, it is clear that Fisher wrote the poem with the primary aim of spreading intellectual illumination. Therefore, through the use of mysticism, the narrator of the poem is able to achieve a mysterious persona that aids with the delivery of the mental provoking ideas of a path into and out of life. "Whatever approaches my passive taking in, then surrounds me and goes by will have itself understood only phase by phase by separate involuntary strokes of my mind, dark swings of a fan-blade that keeps a time of its own" (Fisher 2). From the quoted passage it is evident that Fisher, like most poets and artists, perceives himself as more woke than the general public. As a result, he is able to generate credibility for the narrator, as the use of mysticism at this juncture compels the reader to believe that the poet is more aware of the world than them.

\subsection{Effectiveness}

From the previous analysis, it is apparent that Roy Fisher's poem,AFurnace, employs heavy use of mysticism together with metaphysics. Of course, the author uses these concepts with a purpose while writing the poem. As apparent from the use of mysticism, Fisher is attempting to push forth his main agenda with the poem, which is his description of the structure and design of time. The double spiral path that is traversed through time and through the progression of into and out of life sets the thesis of Fisher's main agenda in the poem. As he describes it, movement through the path of time is not done in a continuous linear motion, but porously, making the future uncertain. As already contested by other scholars, and as discussed in the section above, the non-linear movement through in and out of life would potentially imply that life is a labyrinth or a maze, in which one would get trapped into, never to exit (Bell 156). Such an implication would result in a person living for an eternity, which would overrule the underlying principles of death being inevitable. However, as Fisher puts it, the labyrinth of life has a definite exit and is only made porous by the unforetold nature of events.

Because Fisher knows that such concepts are quite complex to comprehend, he chooses to present them through the use of mysticism. Mysticism comes to his aid in two ways. First and foremost, metaphysics aid in simplifying the esoteric concepts that are presented by Fisher. Fisher wants his readers to imagine and understand the rules and guidelines that govern the entry and exit of human life., Previously, these were topics that were only reserved for religious or heavy philosophical debates. Because of their abstract nature such topics are often avoided. However, Fisher wishes to address these topics in a simplified manner, hence resulting in his use of mysticism. Similar to mysticism, Roy Fisher also uses metaphysics with the same effect. Metaphorically, he incorporates the use of metaphysics into his poem, to express how intellectual illumination in the form of light can be achieved through the knife blade. In other words, Fisher is pointing towards the clichéd 'wokeness' and illumination that can be achieved through given agents. Ideally, Fisher is attempting to illuminate his readers through the use of mysticism and metaphysics.

\subsection{History}

Similar to mysticism, Fisher uses history just as much in his poem, A Furnace, to express his main agenda, which is the double spherical nature of the time design. In the preface of the poem, Fisher uses an excellent introduction, which is outstanding from his recent works. Different from the dynamism in his previous works that did not allow the reader to know where the passages would lead or come from, the passages in AFurnace are well constructed and planned. In the preface Fisher describes the rise and fall of Birmingham, the city in which he lives. He describes Birmingham as a city in which the inhabitants live by the dictations of the authorities. The authorities lead Birmingham as a city that was led to its rise and its falls by the bureaucratic works of the authorities. "Once 
invented, the big city / believed it had a brain; Joe / Chamberlain's sense of the corporate / signaling to itself with millions of disposable / identity-cells, summary and tagged" (Fisher 64).

As evident from the lines of Fisher's poem, it is as though the city of Birmingham was encountering current issues with its governance. As of the present, the big corporation, which is the government, is responsible for the classic divide. As of the present global corporations, in particular social media, are responsible for causing class divides, similar to the ones narrated about by Roy Fisher in his poem (Ingne 53). The use of historical events that can be found in other places of the time streamisessential in conveying Fisher's message as they employ the concept of Heraclitean flux and are ahistorical in nature. The Heraclitean flux is an agreement that was reached upon by Aristotle and Plato that was built upon three concepts. The first principle of stated that everything is in a constant state of change, while the second states that all things that are opposite are also identical (Haydon 98). According to the third principle, everything is at the same time, while not at the same time.

Such a conclusion of comparing Fisher's poem to the Heraclitean flux can be arrived at as per Fisher's explicit pointing out of the matter in his preface for the poem,A Furnace, for the original Oxford University Publication edition (Dorward 68). "A Furnace is an engine devised, like a cauldron, or a still, or a blastfurnace, to invoke and assist natural processes of change; to persuade obstinate substances to alter their condition and show relativities which would otherwise remain hidden by their concreteness" (Spence 89). Such use of obstinate metaphors by Fisher shows that he believes in a cosmological universe where events in history are interconnected as everything is interrelated despite the perceived physical differences.

As AFurnace begins, the narrator is riding atop the deck of a public transit bus that cruises through the suburban areas of Birmingham. "... planted alone above the driver's head. High over the roadway I'm being swung out into an unknown crosswise route to a connection at the Fighting Cocks by way of Ettingshall" (Fisher 2). As the poem comes to an end, it does so with life-affirming images of snails engulfed on snail stalks.Fisher describes the snails feeding upon wild fennel in Ampurias of spain .

The snails ascend

the thin clear light,

taking their spirals higher;

in the dusk

luminous white, clustered

like seed-pods of some other plant;

quietly

rasping their way round

together, and upward;

tight and seraphic.

(Fisher 85).

Fisher takes his readers through different points in time to show that what has happened at a given point in time has the potentiality to occur at a different time frame. Fisher employs the use of history to show relativities that would have otherwise remained obstinate due to their obscurity as they travel through the trajectories of time. There are numerous mentions of events that transpired in different times of history in the poem that are relative in the space of time. For example, he plunders over the final performances of Coleman Hawkins, the great saxophonist.Fisher indicates death in life as he describes Hawkins as,

declining solids, genially

breaking apart,brown man

with papery skin

almost as grey as his

beard and long hair,

the look of a hundred winters

down on his shrunken shoulders

that shake with the mysterious 
mutter and chuckle across the mouthpiece,

(Fisher 72)

He also talks about the history of Birmingham following their war, which is an event that can take place at any place recovering from a war. Such occurrences are obscure as their probability of occurring at different points of time is cannot be exempted.

\subsection{Effectiveness}

History is of significant significance in Roy Fisher's A Furnace. Fisher uses history to cement his previously created concept of the double spiral path through in and out of life. In the structure and design for his double spiral path through life, Fisher pinpoints that the path is not linear, but porous in nature. Through mentioning historical events, Fisher is able to elaborate the non-linear path through in and out of life (Mirabai). TheHeraclitean flux, which states that everything is under a continuous state of change; opposites are the same, and everything is the same and not the same at the same time is credited by his use of history in the poem.

Reference to historical events, such as the rise and fall of Birmingham,is enough proof of this statement. The fact that Birmingham rose and plundered indicates that everything is in a continuous state of change, hence proving the first principle of the Heraclitean flux. Opposites are the same can also be proved because, in the present day, similar situations are also being observed in different parts of the world despite the difference in time and location. Finally, the third principle where everything is the same, while not the same at the same time can also be inferred from the incidents at Birmingham as despite the fact that similar things may be occurring at different parts of the world, they remain different events. Therefore, Fisher's use of history becomes essential in the sense that it aids in the explanation of his concepts. Furthermore, through the use of history, the readers are also able to feel a sense of enlightenment as they relate to historical and current events happening at different time frames. As a result, one of the main agendas of the poem which is to enlighten its readers an audience is achieved.

\section{CONCLUSION}

At the beginning of this essay, a primary aim was established to determine the significance of the use of history and mysticism by Roy Fisher in his poem, $A$ Furnace. The poem has its name symbolically placed, to refer to the abstract nature of the cosmology. In a furnace, all substances are torched to a point where they come to exist as one, despite the massive differences that exist between them. Such are the principles of relativity as things become interrelated despite their differences. Fisher portrays the course of life as a furnace where everything is interconnected, with the paths going in and out being double spiral and porous at the same time. What this means is that events through the puzzle of life may have occurred somewhere else, or bear a resemblance, thus offering an explanation to the nature of life. Fisher's use of mysticism and history has been of great benefit to his work as they have helped simplify his rather complex arguments. Fisher intends to spread intellectual illumination through his poem, and because the subject that he addresses is tough, the use of mysticism and history allow him to provide examples that are simplified for the ordinary reader to be able to grasp his concepts. Therefore, this leads us to the conclusion that the significant importance of mysticism and history in Roy Fisher's AFurnace is to simplify the main points of the poem.

\section{WORKS CITED}

Bell, Larry. "Mystics of Major Historical Importance." Ranker, 2019, https://www.ranker.com/list/important-mysticsin-history/larry-bell-1.

Crook, Paul. "W. R. Inge and Cultural Crisis, 18991920." Journal of Religious History 16 (1991): 410-432.

Dorward, Nate. "Jacket 12 - Nate Dorward - On Roy Fisher". Jacketmagazine.Com, 2000, http://jacketmagazine.com/12/fisher-bydorward.html.

Fisher, R. A Furnace (Oxford: Oxford University Press, 1986) 
Haydon, A. Eustace. "The Significance of the Mystic's Experience." The Journal of Religion, vol. 2, no. 2, 1922, pp. 179-189. JSTOR, www.jstor.org/stable/1195656.

McAuliffe $\mathbf{J}$ et al. "Welcome to The Manchester Review." The Manchester Review, 2019, http://www.themanchesterreview.co.uk/.

Pople, Ian. "Roy Fisher | A Furnace | Reviewed by Ian Pople - The Manchester Review." The Manchester 2019, http://www.themanchesterreview.co.uk/?p=103 60.

Pople, Ian. "Roy Fisher's Mysticism." Research.Manchester.Ac.Uk, 2011, https://www.research.manchester.ac.uk/portal/fi les/54510433/FULL_TEXT.PDF.

Rudolf Otto's classical Mysticism East and West, translated by B. L. Bracey and R. C. Payne (New York and London, 1957, in paperback)

Sidney Spencer, Mysticism in World Religion (Baltimore: Penguin, 1963).

Starr, Mirabai. "Wild Mercy: Living the Fierce and Tender Wisdom ofThe Women Mystics Paperback." Amazon, 2019, https://aax-useast.amazon- https://aax-us-east.amazonadsystem.com/x/c/QmWsigR hBGnUELYXhw 5bcUAAAFuCtLJhgEAAAFKAfRspBI/https:// assoc-

redirect.amazon.com/g/r/https://www.amazon.c om/gp/product/1683641566/?creativeASIN=16 83641566\&linkCode=w61\&imprToken=Esomx gHJ4qTRbLJZbmh9zA\&slotNum=0\&tag=opra h-auto-

20\&ascsubtag $=[\operatorname{artid} \mid 10072 . a .27614027[\operatorname{src} \mid[\mathrm{ch} \mid$ [1t

Vincenty, Samantha. "Signs You Might Be A Mystic." Oprah Magazine, 2019, https:/www.oprahmag.com/life/a27614027/wh at-is-a-mystic/.

W R Ingne Mysticism in Religion (London, 1907) https://www.encyclopedia.com/humanities/ency clopedias-almanacs-transcripts-and-maps/ingewilliam-ralph-1860-1954 